\title{
Peripheral polyneuropathy in severely obese patients with metabolic syndrome but without diabetes: Association with low HDL-cholesterol
}

\author{
Otto Henrique Nienov ${ }^{1}$, Luciana Matte ${ }^{2}$, Lisiane Stefani Dias ${ }^{1,2}$, Helena Schmid ${ }^{1,2,3 *}$ \\ ${ }^{1}$ Health Sciences Graduate Program, Obstetrics and Gynecology, Universidade Federal do Rio Grande do Sul, Porto Alegre, RS, Brazil \\ ${ }^{2}$ Health Sciences Graduate Program, Universidade Federal de Ciências da Saúde de Porto Alegre, Porto Alegre, RS, Brazil \\ ${ }^{3}$ Department of Internal Medicine, Hospital de Clínica de Porto Alegre. Obesity Treatment Center, Hospital Santa Rita, Complexo Hospitalar Santa Casa de Misericórdia de Porto Alegre, Porto Alegre, RS, Brazi
}

Study conducted at Obesity Treatment Center, Hospital Santa Rita, Complexo Hospitalar Santa Casa de Misericórdia de Porto Alegre, Porto Alegre, RS, Brazil

Article received: $10 / 7 / 2016$ Accepted for publication: 12/1/2016

*Correspondence: Departamento de Medicina Interna, Hospital de Clínicas de Porto Alegre Address: Rua Ramiro Barcelos, $2.350 / 700$

Porto Alegre, RS - Brazil Postal code: 90035-903 schmidhelena@yahoo.com.br

\section{SUMmARY}

Introduction: The purpose of this study was to evaluate the prevalence of peripheral polyneuropathy (PPN) in subjects with grade II and III obesity (Ob-II,III) and metabolic syndrome (MetS) but without diabetes and to investigate possible associated factors.

Method: A cross-sectional study was performed in non-diabetic Ob-II,III,MetS patients using the Michigan Neuropathy Screening Instrument (MNSI) to assess the presence of PPN.

Results: A total of 24 of 218 non-diabetic Ob-II,III,MetS patients had PPN. Based on univariate analysis, serum levels of LDL-cholesterol ( $p=0.046)$ were significantly associated with PPN, while serum triglycerides $(\mathrm{p}=0.118)$ and low HDL-cholesterol $(\mathrm{p}=0.057)$ showed a tendency toward this association. On a Poisson regression analysis, when the three possible associations were included, low HDL-cholesterol $(\mathrm{p}=0.047)$ remained independently associated.

Conclusion: In non-diabetic Ob-II,III,MetS patients, PPN defined by the MNSI showed a high prevalence and was associated with low levels of HDL-cholesterol. In order to diagnose that complication, neurological evaluation should be performed in these patients.

Keywords: polyneuropathies, obesity, metabolic syndrome, HDL cholesterol.

\section{INTRODUCTION}

Clinical trial results have shown that intensive metabolic control reduces the incidence and progression of neuropathy in patients with type 1 diabetes mellitus (DM1). Yet, for patients with type 2 diabetes mellitus (DM2), it is unclear that glycemic control has such a striking effect, although other microvascular complications can be clearly prevented. Since polyneuropathy occurring in patients with DM2 has been related to risk factors such as obesity, dyslipidemia, peripheral arterial disease, vitamin deficiencies and pre-diabetes, these and other factors often associated with DM2 presence could have a relevant impact as a determinant of disease onset and progression. ${ }^{1-3}$

Currently, few studies have investigated the association and risk factors for progression of peripheral polyneuropathy $(\mathrm{PPN})$ in non-diabetic severely obese patients with metabolic syndrome (MetS). If in DM2 these associations have a great impact on PPN, patients who have them, even before presenting metabolic changes consistent with the diagnosis of DM, could already present PPN. Therefore, knowing the prevalence of PPN and its risk factors in patients with predisposition to DM could be useful to define the determining factors of PPN in obese patients with and without DM2. Considering the aspects above, we sought to establish the prevalence of PPN in obese patients grade II and III with MetS and without DM (non-diabetic Ob-II,III,MetS patients) in which possible risk factors such as hyperglycemia, dyslipidemia, increased body weight or waist circumference, use of metformin and decreased serum vitamin B12 levels could be associated with presence of PPN as defined by the Michigan Neuropathy Screening Instrument (MNSI). 


\section{MetHOD}

\section{Subjects}

A cross-sectional and prospective study including patients with grade II and III obesity (severe obesity) with MetS and without diabetes was conducted in the Obesity Treatment Center at Santa Rita Hospital, Santa Casa de Misericórdia de Porto Alegre Hospital Complex, in the period of January to December 2014. The studied subjects underwent tests and consultations according to a surgical protocol to undergo bariatric surgery. Patients were evaluated consecutively during their routine visits by two biomedical examiners who were unaware of the comorbidities related to obesity or dyslipidemia and MetS components presented by the patients. The following inclusion criteria were adopted: minimum age of 18 years; grade II and III obesity as defined by the World Health Organization $(\mathrm{WHO})^{4}\left(\mathrm{BMI} \geq 35\right.$ to $39.9 \mathrm{~g} / \mathrm{m}^{2}$ and $\mathrm{BMI} \geq 40 \mathrm{~kg} /$ $\mathrm{m}^{2}$, respectively); MetS as defined by the International Diabetes Federation (IDF); $;^{5}$ absence of DM according to parameters of the American Diabetes Association (ADA); ${ }^{6}$ and consent form signed for participation in the study. Exclusion criteria were: hypothyroidism (TSH levels greater than $6 \mathrm{mU} / \mathrm{L}$ ); vitamin B12 deficiency (serum levels below $210 \mathrm{pg} / \mathrm{mL}$ ); prior bariatric surgery; history of alcohol abuse according to the CAGE questionnaire; ${ }^{7}$ creatinine clearance less than $60 \mathrm{~mL} / \mathrm{min}$ according to the Cockcroft-Gault equation; ${ }^{8}$ acute liver disease; leprosy; HIV positive test; nursing mothers and pregnant women; fasting glucose or A1c hemoglobin levels suggesting diagnosis of DM on the date of inclusion.

The following information was obtained from the patients' medical charts in the last three months of assessment for neuropathy: anthropometric data and blood pressure $(\mathrm{mmHg})$, serum blood glucose $(\mathrm{mg} / \mathrm{dL})$ checked after fasting and again two hours after drinking a glucose-rich drink, HDL-cholesterol (mg/dL), LDL-cholesterol $(\mathrm{mg} / \mathrm{dL})$, triglycerides $(\mathrm{mg} / \mathrm{dL})$, creatinine $(\mathrm{mg} / \mathrm{dL})$, TSH $(\mathrm{mU} / \mathrm{L})$, and vitamin B12 $(\mathrm{pg} / \mathrm{mL})$. After authorizing their participation in the study, patients were asked to complete the questionnaire, which comprised questions regarding presence of neuropathy - the MNSI. ${ }^{9,10}$ The first measures assessed were degree of neuropathy according to the MNSI and waist circumference. Impaired glucose intolerance was defined according to the ADA criteria. ${ }^{6}$

Metabolic syndrome was characterized according to the IDF criteria, ${ }^{5}$ and was considered present with waist circumference $\geq 80 \mathrm{~cm}$ for women and $\geq 94 \mathrm{~cm}$ for men in addition to at least two of the following risk factors: triglycerides $\geq 150 \mathrm{mg} / \mathrm{dL}$, HDL-cholesterol $<40 \mathrm{mg} / \mathrm{dL}$ for men and $<50 \mathrm{mg} / \mathrm{dL}$ for women, systolic blood pres- sure $\geq 130 \mathrm{mmHg}$ or diastolic blood pressure $\geq 85 \mathrm{mmHg}$, fasting glucose $\geq 100 \mathrm{mg} / \mathrm{dL}$, previous diagnosis of DM and hypertension or patient undergoing treatment for hypertension or DM.

LDL-cholesterol was defined as increased if $>130 \mathrm{mg} / \mathrm{dL}$, fasting blood glucose $\geq 100 \mathrm{mg} / \mathrm{dL}$ and $<126 \mathrm{mg} / \mathrm{dL}$ was categorized as impaired glucose tolerance (IGT) ${ }^{6}$ blood glucose 2 hours after oral intake of $75 \mathrm{~g}$ of glucose $\geq 140 \mathrm{mg} / \mathrm{dL}$ and $<200 \mathrm{mg} / \mathrm{dL}$ was defined as IGT, ${ }^{11}$ and creatinine $>1.4 \mathrm{mg} / \mathrm{dL}$ was defined as chronic renal disease.

Of the 315 patients, 67 were excluded for having diabetes, 23 for not meeting the criteria for MetS, three for having hypothyroidism, three for having had bariatric surgery in the past and one for having vitamin B12 deficiency. In the end, 218 individuals remained in the study.

\section{Ethical aspects}

The study was approved by the Research Ethics Committee of the Santa Casa de Misericórdia de Porto Alegre Hospital Complex and all patients were informed about this research through a Free and Informed Consent Form, according to resolution 466/2012.

\section{Instruments}

MNSI was used to assess the presence and degree of neuropathy. ${ }^{9,10}$ This instrument was validated and yielded a specificity of $79 \%$ and a sensitivity of $61 \%{ }^{9}$

The MNSI questionnaire for symptoms consists of 15 questions, which were translated into Brazilian Portuguese and used to track PPN symptoms. The maximum amount of points scored by patients was 13 , since questions 4 and 10 serve to assess association with peripheral vascular disease and asthenia, respectively.

The MNSI physical examination was conducted in a comfortable and calming room of the OTC, with temperature ranging between $22^{\circ} \mathrm{C}$ and $26^{\circ} \mathrm{C}$. The patients remained seated or at supine position lying comfortably and blindfolded in order to raise the perception. A physician of our team was trained to perform this test at the University of Michigan, further instructing two of our $\mathrm{PhD}$ students on performing this neurological evaluation. These two biomedical scientists performed all of the tests and in case of discrepancies the physician also examined the patient and made the final decision. Examiners were blinded for the results of laboratory exams while performing the physical examination. In the physical exam, points were awarded according to results of appearance of feet, vibratory sensitivity on the hallux, sensitivity to Semmes-Weinstein monofilament applied in the same location of the tuning fork, and blow with a neurological hammer on the Achilles 
tendon, just above its insertion on the calcaneus, with the patient seated and with his legs dangling (Achilles reflex). As for feet abnormalities and presence of ulceration, one point was awarded to each if the sign was present and zero point if it was absent. On the other results, one point was given when the response was absent; half a point when presented with reinforcement or decreased and zero point when present, even with reinforcement (Figure 1). In all, the points were added and a cutoff of 2.5 or more (cutoff validated for the MNSI) was defined as suggestive of neuropathy. ${ }^{9}$

\section{Statistical analysis}

The statistical analysis plan was defined prior to data acquisition.

Then, a univariate descriptive analysis was performed, in which all the quantitative data were described using medians and the qualitative data were described by its frequency. All categorical data were tested using Chi-square test or Fisher's exact test, if appropriate. Continuous variables were first tested using the Shapiro-Wilk test followed by Student's t-test to compare the average in case of normal distribution of the data. Mann-Whitney test was used when the distribution was not normal. Significant difference was considered when $\mathrm{p} \leq 0.05$.

After the univariate analysis, a Poisson regression analysis was performed to assess which of the factors studied were independently associated with the occurrence of PPN. The combination of measures was evaluated using a prevalence ratio with $95 \%$ confidence interval. Variables included in the model were those that in the univariate analysis had a result of $\mathrm{p} \leq 0.2$. The statistical program used was SPSS for Windows, version 18.

\section{Results}

In our study, all patients with physical exam positive for PPN presented at least one symptom of neuropathy. An $11 \%$ prevalence $(\mathrm{n}=24)$ of PPN was found in non-diabetic Ob-II,III,MetS individuals. In this study, $81.2 \%$ of individuals with obesity grade II and III with MetS and without DM were female. In Table 1, we verified features of the 218 individuals evaluated for PPN presence, according to MNSI.

According to the data obtained, there was a tendency towards higher frequency of low HDL-cholesterol in the neuropathy group compared to the non-neuropathy group $(\mathrm{p}=0.057)$. In both groups, most subjects had grade III obesity ( $75 \%$ vs. $73.2 \%$, respectively). There were no significant differences between neuropathic and non-neuropathic patients regarding number of individuals with systemic arterial hypertension $(\mathrm{SAH})(\mathrm{p}=0.239)$, high levels of LDL-cholesterol $(\mathrm{p}=0.341)$, hypertriglyceridemia $(\mathrm{p}=0.219)$, impaired fasting glucose $(\mathrm{p}=0.610)$, use of metformin $(\mathrm{p}=0.606)$ and pre-diabetes or IGT $(\mathrm{p}=0.954)$.

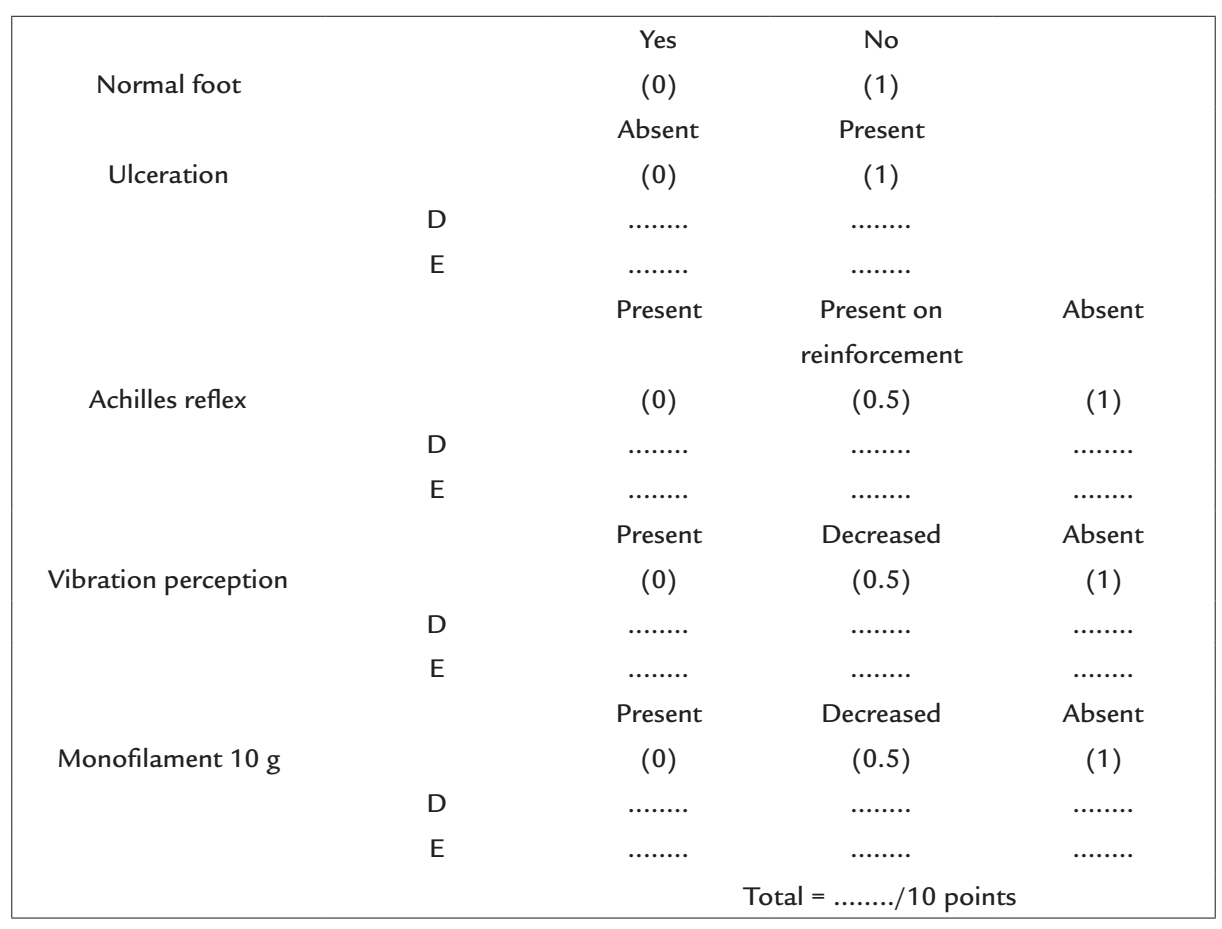

FIGURE 1 Physical exam of the MNSI. 
TABLE 1 Characteristics of 218 patients with MetS, degree II and III obesity and without DM, assessed for the PPN presence $(\geq 2.5)$. The numbers shown are the total number of patients with the condition described in each group. The percentage of patients with the condition described in each group is shown in the parentheses.

\begin{tabular}{|c|c|c|c|}
\hline & PPN Group $(n=24)$ & No PPN Group $(n=194)$ & p-value \\
\hline Female sex (\%) & $19(79.2)$ & $158(81.4)$ & $0.784^{b}$ \\
\hline Degree II obesity $(\%)^{c}$ & $6(25.0)$ & $52(26.8)$ & $1.000^{\mathrm{a}}$ \\
\hline Degree III obesity $(\%)^{c}$ & $18(75.0)$ & $142(73.2)$ & \\
\hline SAH (\%) & $15(62.5)$ & $92(47.4)$ & $0.239^{a}$ \\
\hline Low HDL-c (\%) & $22(91.7)$ & $138(71.1)$ & $0.057^{a}$ \\
\hline High LDL-c (\%) & $5(20.8)$ & $25(12.9)$ & $0.341^{b}$ \\
\hline Hypertriglyceridemia (\%) & $14(58.3)$ & $83(42.8)$ & $0.219^{a}$ \\
\hline High fasting blood glucose (\%) & $6(25.0)$ & $63(32.5)$ & $0.610^{\mathrm{a}}$ \\
\hline High blood glucose $2 \mathrm{~h}$ post-intake of $75 \mathrm{~g}$ of glucose (\%) & $6 / 21(28.6)$ & $57 / 179(31.8)$ & $0.954^{\mathrm{a}}$ \\
\hline Metformin use (\%) & $0(0.0)$ & $10(5.2)$ & $0.606^{\mathrm{b}}$ \\
\hline $\begin{array}{l}\text { 'Chi-Squared test. } \\
\text { 'Fisher's exact test. } \\
\text { EMMI: body mass index. } \\
\text { SAH: systemic arterial hypertension; HDL-c: high-density lipoprotein ch }\end{array}$ & 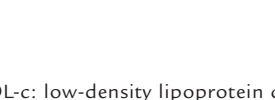 & 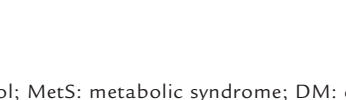 & (1) \\
\hline
\end{tabular}

Table 2 shows anthropometric and clinical data expressed as median, evaluated for the presence of PPN according to MNSI. The group with neuropathy showed higher serum levels of LDL-cholesterol compared to those without neuropathy $(\mathrm{p}=0.046)$. There was a tendency towards higher serum levels of triglycerides in the neuropathy group compared to the non-neuropathy group ( $\mathrm{p}=0.118$ ).

On the other hand, there was no significant difference between the results of neuropathy and non-neuropathy groups, respectively, on: age ( 34.5 years vs. 34 years, $\mathrm{p}=0.350)$, height (1.66 m vs. $1.63 \mathrm{~m}, \mathrm{p}=0.866)$, weight $(118 \mathrm{~kg}$ vs. $116 \mathrm{~kg}, \mathrm{p}=0.443), B M I\left(44.9 \mathrm{~kg} / \mathrm{m}^{2}\right.$ vs. $42.5 \mathrm{~kg} / \mathrm{m}^{2}$, $\mathrm{p}=0.207)$, waist circumference $(123 \mathrm{~cm}$ vs. $122 \mathrm{~cm}, \mathrm{p}=0.374)$, systolic blood pressure (SBP) $(130 \mathrm{mmHg}$ vs. $130 \mathrm{mmHg}$, $\mathrm{p}=0.852)$, diastolic blood pressure (DBP) $(80 \mathrm{mmHg}$ vs. $80 \mathrm{mmHg}, \mathrm{p}=0.341)$, mean blood pressure (MBP) (96.7 mmHg vs. $96.7 \mathrm{mmHg}, \mathrm{p}=0.442$ ), fasting blood glucose (89.4 mg/dL vs. $93.8 \mathrm{mg} / \mathrm{dL}, \mathrm{p}=0.273)$, blood glucose 2 hours after oral intake of $75 \mathrm{~g}$ of glucose $(126 \mathrm{mg} / \mathrm{dL}$ vs. $126 \mathrm{mg} / \mathrm{dL}, \mathrm{p}=0.889)$, HDL-cholesterol (43.5 mg/dL vs. $45 \mathrm{mg} / \mathrm{dL}, \mathrm{p}=0.457)$, creatinine $(0.82 \mathrm{mg} / \mathrm{dL}$ vs. $0.8 \mathrm{mg} / \mathrm{dL}$, $\mathrm{p}=0.965)$, TSH (2.5 mU/L vs. $2.2 \mathrm{mU} / \mathrm{L}, \mathrm{p}=0.437)$ and vitamin B12 (416 pg/mL vs. 449 pg/mL, $\mathrm{p}=0.432$ ).

Based on the evaluated data, we performed a multivariate Poisson regression (Table 3 ) in order to assess which of the factors were independently associated with the occurrence of PPN in non-diabetic Ob-II,III,MetS individuals.

In the model, the variables used were low HDL-cholesterol, serum levels of LDL-cholesterol and triglycerides. PPN was associated independently with low HDL-cholesterol $(\mathrm{p}=0.047)$, but there was no association with serum levels of LDL-cholesterol $(\mathrm{p}=0.118)$ and triglycerides $(\mathrm{p}=0.239)$.

\section{Discussion}

Few studies assess the prevalence of PPN and factors associated to it in severe obesity and metabolic syndrome patients. This study aimed to evaluate the prevalence and some factors that could be associated with PPN in both men and women with severe obesity and MetS without DM. We observed an $11 \%$ prevalence of PPN in our sample with no difference in gender prevalence. Ylitalo et al., looking into data from men and women in the NHANES study, found a $10.9 \%$ prevalence of PPN in the obese group. ${ }^{12}$ Although we found a similar number of individuals with PPN, it seems important to identify differences between Ylitalo's study and ours. In the comparative study, participants were older than 40 years, obesity was determined by a lower BMI $\left(\geq 30 \mathrm{~kg} / \mathrm{m}^{2}\right)$ and participants were not selected for the presence of MetS. Moreover, diabetic patients were not excluded and the presence of PPN was evaluated using Semmes-Weinstein monofilament applying pressure on three different points at the plantar surface of each foot (method which identifies neuropathy only later than the majority of other methods).

In the literature, data is not consistent when considering the prevalence of PPN in subjects without diabetes. Singleton et al. evaluated 107 patients with idiopathic neuropathy and obtained a 34\% prevalence of IGT individuals, of which $92 \%$ had neuropathic pain and $81 \%$ had sensory complaints. ${ }^{13}$ Smith and Singleton found a $45 \%$ prevalence of pre-diabetes in patients with idiopathic 
TABLE 2 Anthropometric and clinical data of 218 patients with MetS, degree II and III obesity, and without DM, assessed for the presence of PPN. These figures represent the median. The values in parentheses correspond to $25 \%$ and $75 \%$ quartiles, respectively.

\begin{tabular}{llll} 
& PPN Group $(\mathbf{n}=24)$ & No PPN Group (n=194) & P-value \\
\hline Age $($ years $)$ & $34.5(31.5 ; 43.8)$ & $34(29 ; 40.3)$ & 0.350 \\
\hline Height $(\mathrm{m})$ & $1.66(1.60 ; 1.68)$ & $1.63(1.58 ; 1.70)$ & 0.866 \\
\hline Weight $(\mathrm{kg})$ & $118(104 ; 139)$ & $116(104 ; 128)$ & 0.443 \\
\hline BMI $\left(\mathrm{kg} / \mathrm{m}^{2}\right)$ & $44.9(39.4 ; 50.8)$ & $42.5(39.9 ; 46.3)$ & 0.207 \\
\hline Waist circumference $(\mathrm{cm})$ & $123(118 ; 136)$ & $122(116 ; 131)$ & 0.374 \\
\hline SBP $(\mathrm{mm} / \mathrm{Hg})$ & $130(120 ; 140)$ & $130(120 ; 140)$ & 0.852 \\
\hline DBP $(\mathrm{mm} / \mathrm{Hg})$ & $80(72.5 ; 90)$ & $80(80 ; 90)$ & 0.341 \\
\hline MBP $(\mathrm{mm} / \mathrm{Hg})$ & $96.7(93.3 ; 102)$ & $96.7(93.3 ; 103)$ & 0.442 \\
\hline Fasting blood glucose $(\mathrm{mg} / \mathrm{dL})$ & $89.4(82 ; 99.8)$ & $93.8(86.8 ; 101)$ & $126(106 ; 146)$ \\
\hline Blood glucose $2 \mathrm{~h} \mathrm{post-intake} \mathrm{of} 75 \mathrm{~g}$ of glucose $(\mathrm{mg} / \mathrm{dL})$ & $126(113 ; 147)$ & $45(39 ; 50)$ & 0.273 \\
\hline HDL-c $(\mathrm{mg} / \mathrm{dL})$ & $43.5(37 ; 49)$ & $111(89 ; 133)$ & 0.889 \\
\hline LDL-c $(\mathrm{mg} / \mathrm{dL})$ & $128(110 ; 144)$ & $132(99 ; 192)$ & 0.457 \\
\hline Triglycerides $(\mathrm{mg} / \mathrm{dL})$ & $172(97 ; 247)$ & $0.80(0.70 ; 0.94)$ & $0.046 *$ \\
\hline Creatinine $(\mathrm{mg} / \mathrm{dL})$ & $0.82(0.75 ; 0.90)$ & $2.2(1.6 ; 3.0)$ & 0.118 \\
\hline TSH $(\mathrm{mU} / \mathrm{L})$ & $2.5(1.5 ; 4.5)$ & $449(328 ; 655)$ & 0.965 \\
\hline B12 vitamin $(\mathrm{pg} / \mathrm{mL})$ & $416(343 ; 507)$ & 0.437 \\
\hline
\end{tabular}

*Statistically significant $(p<0.05)$

Mann-Whitney U test.

BMI: body mass index; SBP: systolic blood pressure; DBP: diastolic blood pressure; MBP: mean blood pressure; HDL-c: high-density lipoprotein cholesterol; LDL-c: low-density lipoprotein cholesterol; MetS: metabolic syndrome; DM: diabetes mellitus; PPN: peripheral polineuropathy.

TABLE 3 Multivariate Poisson regression, in order to evaluate which factors were independently associated to the occurrence of PPN in the sample of degree II and III obesity patients with MetS and without DM.

\begin{tabular}{|c|c|c|}
\hline \multirow[t]{2}{*}{ Variables } & \multicolumn{2}{|l|}{ Model } \\
\hline & PR $(95 \mathrm{Cl})$ & p-value \\
\hline Low HDL-c & $4.12(1.02-16.7)$ & $0.047^{*}$ \\
\hline LDL-c & $1.01(1.00-1.02)$ & 0.118 \\
\hline Triglycerides $(\mathrm{mg} / \mathrm{dL})$ & $1.00(0.99-1.01)$ & 0.239 \\
\hline
\end{tabular}

sensory neuropathy. ${ }^{14}$ Ziegler et al. found a $13 \%$ prevalence of PPN in individuals with pre-diabetes, $11.7 \%$ in those with impaired fasting blood glucose and $7.4 \%$ in normal patients. ${ }^{15}$ A study performed between 1999 and 2004 in individuals aged over 40 years has shown that, compared with patients without diabetes, pre-diabetic subjects had $11 \%$ higher risk of PPN. ${ }^{16}$ Other groups have also revealed higher than expected prevalence of pre-diabetes in patients with idiopathic neuropathy in comparison with data of the healthy population. ${ }^{17}$

In our study, no difference was found between the percentage of patients with positive criteria for pre-diabetes (fasting hyperglycemia and altered hyperglycemia 2 hours after $75 \mathrm{~g}$ oral glucose intake in groups with and without neuropathy), which suggests that the loss of glycemic control is not the only mechanism determining PPN in the group with neuropathy. In addition, there was no association on univariate analysis between presence of PPN and gender, age, weight, height, BMI, waist circumference, SBP, DBP, MBP and serum levels of HDL-cholesterol, creatinine, TSH and $\mathrm{B} 12$ vitamin.

After a multivariate Poisson regression using low HDL-cholesterol and serum levels of LDL-cholesterol and triglycerides, only low HDL-cholesterol was demonstrated to be independently associated with the presence of PPN. Considering this study model, severely obese individuals with MetS and without DM with low HDL-cholesterol had approximately four times higher prevalence of PPN. This result is in accordance with the observation by Callaghan et al. that triglyceride levels were positively related to the risk of amputation in patients with DM2 and that HDL-cholesterol levels between 40-59 mg/dL confer protection against the probability of a lower limb amputation. ${ }^{18}$

Tesfaye et al. found cardiovascular risk factors associated with the development of neuropathy, such as BMI and serum levels of total cholesterol, LDL-cholesterol and triglycerides, ${ }^{19}$ but in the KORA study, ${ }^{20}$ serum triglycerides were not associated with neuropathic pain. In another research, there was an association of triglyc- 
erides with lower limb amputation, but no association with LDL and HDL-cholesterol. ${ }^{18}$ We observed that, although there was initially a significant association between serum levels of LDL-cholesterol and a tendency of association between serum triglyceride levels with the presence of PPN, this association was not confirmed in the multivariate regression.

Our study raised the hypothesis that non-diabetic Ob-II,III,MetS patients and with PPN would have lower levels of vitamin B12 compared to those without PPN and that there would be an association with the use of metformin, since some pre-diabetic patients receive this prescription in order to prevent progression to DM. However, the results showed no association between the presence of PPN and vitamin B12 levels or use of metformin.

Since we showed a significant prevalence of PPN in severely obese subjects with MetS without diabetes and a significant association of PPN with low HDL-cholesterol, we considered this finding as the most consistent in our study and we will make some considerations about this possibility.

In addition to being a marker for future ${ }^{21}$ or concurrent $^{22}$ cardiovascular disease, low HDL-cholesterol is also associated with many clinical parameters such as low levels of physical activity.22 Thus, the main recommendation made to increase HDL-cholesterol is physical exercise. ${ }^{23-25}$ Since a study conducted by our research group showed that 1 year of Roux-en-Y gastric bypass decreased serum levels of blood glucose, total cholesterol, LDL-cholesterol and triglycerides, but did not improve HDL cholesterol, ${ }^{26}$ it is also possible that PPN described after this kind of bariatric surgery by other author ${ }^{27}$ could be related to the low HDL-cholesterol levels that these sedentary patients usually present, as well as to vitamin deficiency.

Clinical and epidemiological studies have shown that HDL, a class of plasma lipoproteins, can be very heterogeneous in size and density, and have an atheroprotective role attributed to its ability to promote efflux of cholesterol from arterial macrophages loaded with cholesterol. ${ }^{28,29}$ However, recent studies have recognized great physical heterogeneity of HDL, which is associated with its multiple functions. Both the protein and lipid components of these particles are involved in its effect. The apolipoprotein AI (ApoA-I) is quantitatively the major protein constituent having a structure suitable for transporting lipids. It readily interacts with the ATP-binding cassette transporter A1 (ABCA1) and the scavenger-receptor B-1 (SR-B1), and it activates the enzyme lecithin-cholesterol acyl transferase (LCAT), which is essential for HDL maturation. The resulting primary mature particles are HDL2 and HDL3. Moreover, ApoA-1 has antioxidant and anti-inflammatory properties, together with other enzymes. Regarding lipid fraction, an atheroprotective role has been recognized for lisosphingolipids, particularly sphingosine-1-phosphate (S1P), which is involved in the process of cholesterol reverse transfer. All these atheroprotective functions are apparently lost in the plasma of patients with systemic inflammation, coronary heart disease, diabetes and chronic kidney disease, as these patients' plasma is considered dysfunctional. ${ }^{28-30}$ When HDL-cholesterol levels are low, as observed in our patients classified as neuropathic, the atheroprotective effect of HDL-cholesterol is probably also decreased.

On the other hand, it has been observed in vitro that HDL-cholesterol particles can be captured by injured distal axons and used for the regeneration of these fibers. ${ }^{31}$ If the uptake of HDL from plasma through binding with SR-B1 receptors previously described as present in distal axons also occurs in vivo, lower peripheral axonal regeneration can take place in patients with low HDL-cholesterol, which would explain our findings.

Increased physical activity of animals has been associated with better autonomic function and could prevent the decrease of nerve function related to aging when they exercise on a regular basis. ${ }^{32,33}$ In humans, in whom the presence of denervation was assessed by skin biopsy and study of intra-dermal nerves, it was observed that lifestyle changes (exercise and diet) determined not only improvement of the lipid abnormalities but also an increase of nerve fibers density in a subsequent biopsy. ${ }^{34,35}$ These data, as well as the findings of our study, suggest that HDL-cholesterol could be either a mediator involved in this effect or a marker that indicates little physical activity, genetic predisposition to atherosclerosis, and other alterations, for example, increased oxidative stress (which would favor neuronal dysfunction). If our findings are later confirmed in studies with other population samples and other designs, there would be a common explanation for the etiology of neuropathy in sedentary subjects, especially when they are obese, with MetS and/or with DM2.

In our study, no difference was found between men and women for the presence of PPN and other studied variables. The low number of men with PPN in our sample population limited our evaluation. Increasing the number of men in the neuropathic group would allow us to analyze if all associated factors found would associate in both sexes or if any of these would prevail in male or female. Since men have a mean HDL-cholesterol level lower than that of normal women, it is possible that the higher prevalence of neuropathy and amputations found 
in other studies in men is a reflection of lower HDL-cholesterol levels. Another limitation for assessing this relationship is the study design, which is cross-sectional. In a longitudinal study performed with a larger number of non-diabetic Ob-II,III,MetS patients with PPN, other associations or risk factors might be found. Therefore, cross-sectional studies with a larger sample and a higher number of men, as well as longitudinal studies, would be necessary to confirm that PPN is associated with low serum HDL-cholesterol and whether there are other associated risk factors for PPN in these patients.

\section{Conclusion}

Our study revealed an $11 \%$ prevalence of PPN in individuals with obesity grade II and III with MetS and not diagnosed with diabetes, and the presence of PPN was independently associated with low HDL-cholesterol levels. Since an increase in HDL-cholesterol is rarely achieved with the treatment of these patients, PPN often progresses in these cases, especially in patients that will become hyperglycemic or develop DM. In order to diagnose this complication, a neurological evaluation should be done when patients come for outpatient visits.

\section{Resumo}

Polineuropatia periférica em pacientes obesos graves com síndrome metabólica sem diabetes: associação com baixo HDL-colesterol

Objetivo: Avaliar a prevalência da polineuropatia periférica (PNP) em indivíduos obesos graus II e III com síndrome metabólica (Ob-II,III,SM) sem diabetes e buscar possíveis fatores associados.

Método: Em um estudo transversal, realizado em indivíduos Ob-II,III,SM e sem diagnóstico de diabetes, o Instrumento de Screening de Michigan (MNSI) foi utilizado para avaliar a presença de PNP.

Resultados: Um total de 24 de 218 pacientes Ob-II,III,SM e sem diabetes tinham PNP. Quando observamos as associações com PNP em uma análise univariada, níveis séricos de LDL-colesterol $(\mathrm{p}=0.046)$ estiveram significativamente associados e houve também uma tendência à associação com níveis séricos de triglicerídeos $(\mathrm{p}=0.118)$ e baixo HDL-colesterol ( $\mathrm{p}=0.057$ ). Em uma análise de regressão de Poisson, quando as três possíveis associações foram incluídas, baixo HDL-colesterol ( $\mathrm{p}=0.047)$ manteve-se independentemente associado.

Conclusão: Em pacientes Ob-II,III,SM, mas sem diabetes, a PNP definida pelo MNSI tem uma prevalência elevada e está associada a baixos níveis de HDL-colesterol. Para diagnóstico dessa complicação, recomenda-se realizar o exame neurológico desses pacientes.

Palavras-chave: polineuropatias, obesidade, síndrome metabólica, HDL-colesterol.

\section{REFEREnCES}

1. The effect of intensive treatment of diabetes on the development and progression of long-term complications in insulin-dependent diabetes mellitus. The Diabetic Control and Complications Trial Research Group. N Engl J Med. 1993; 329(14):977-86.

2. The effect of intensive diabetes therapy on the development and progression of neuropathy. The Diabetic Control and Complications Trial Research Group. Ann Intern Med. 1995; 122(8):561-8.

3. Intensive blood-glucose control with sulphonylureas or insulin compared with conventional treatment and risk of complications in patients with type 2 diabetes (UKPDS 33). UK Prospective Diabetes Study (UKPDS) Group. Lancet. 1998; 352(9131):837-53.

4. World Health Organization. What is overweight and obesity? Geneva: WHO; 2016.

5. International Diabetes Federation. IDF Worldwide definition of the Metabolic Syndrome; 2015. Available from: http://www.idf.org/metabolic-syndrome.

6. American Diabetes Association. Classification and Diagnosis of Diabetes. Diabetes Care. 2016; 39 (Suppl 1):S13-22.

7. Buchsbaum DG, Buchanan RG, Centor RM, Schnoll SH, Lawton MJ. Screening for alcohol abuse using CAGE scores and likelihood ratios. Ann Intern Med. 1991; 115(10):774-7.

8. Cockcroft DW, Gault MH. Prediction of creatinine clearance from serum creatinine. Nephron. 1976; 16(1):31-41.

9. Herman WH, Pop-Busui R, Braffett BH, Martin CL, Cleary PA, Albers JW, et al.; DCCT/EDIC Research Group. Use of the Michigan Neuropathy Screening Instrument as a measure of distal symmetrical peripheral neuropathy in Type 1 diabetes: results from the Diabetes Control and Complications Trial/Epidemiology of Diabetes Interventions and Complications. Diabet Med. 2012; 29(7):937-44.

10. Moghtaderi A, Bakhshipour A, Rashidi H. Validation of Michigan neuropathy screening instrument for diabetic peripheral neuropathy. Clin Neurol Neurosurg. 2006; 108(5):477-81.

11. Russell JW, Feldman EL. Impaired glucose tolerance - does it cause neuropathy? Muscle Nerve. 2001; 24(9):1109-12.

12. Ylitalo KR, Sowers M, Heeringa S. Peripheral vascular disease and peripheral neuropathy in individuals with cardiometabolic clustering and obesity: National Health and Nutrition Examination Survey 2001-2004. Diabetes Care. 2011; 34(7):1642-7.

13. Singleton JR, Smith AG, Bromberg MB. Increased prevalence of impaired glucose tolerance in patients with painful sensory neuropathy. Diabetes Care. $2001 ; 24(8): 1448-53$.

14. Smith AG, Singleton JR. The diagnostic yield of a standardized approach to idiopathic sensory-predominant neuropathy. Arch Intern Med. 2004; 164(9):1021-5.

15. Ziegler D, Rathmann W, Dickhaus T, Meisinger C, Mielck A; KORA Study Group. Prevalence of polyneuropathy in pre-diabetes and diabetes is associated with abdominal obesity and macroangiopathy: the MONICA/KORA Augsburg Surveys S2 and S3. Diabetes Care. 2008; 31(3):464-9.

16. Katon JG, Reiber GE, Nelson KM. Peripheral neuropathy defined by monofilament insensitivity and diabetes status: NHANES 1999-2004. Diabetes Care. 2013; 36(6):1604-6.

17. Smith AG. Impaired glucose tolerance and metabolic syndrome in idiopathic neuropathy. J Peripher Nerv Syst. 2012; 17(Suppl 2):15-21.

18. Callaghan B, Feldman E, Liu J, Kerber K, Pop-Busui R, Moffet H, et al. Triglycerides and amputation risk in patients with diabetes: ten-year follow-up in the DISTANCE study. Diabetes Care. 2011; 34(3):635-40.

19. Tesfaye S, Chaturvedi N, Eaton SEM, Ward JD, Manes C, Ionescu-Tirgoviste C, et al. Vascular risk factors and diabetic neuropathy. N Engl J Med. 2005; 352(4):341-50. 
20. Ziegler D, Rathmann W, Meisinger C, Dickhaus T, Mielck A; KORA Study Group. Prevalence and risk factors of neuropathic pain in survivors of myocardial infarction with pre-diabetes and diabetes. The KORA Myocardial Infarction Registry. Eur J Pain. 2009; 13(6):582-7.

21. Hayashi T, Kawashima S, Itoh H, Yamada N, Sone H, Watanabe H, et al. Low HDL cholesterol is associated with the risk of stroke in elderly diabetic individuals: changes in the risk for atherosclerotic diseases at various ages. Diabetes Care. 2009; 32(7):1221-3.

22. Reiner Z, Muacević-Katanec D, Katanec D, Tedeschi-Reiner E. [Low HDL-cholesterol - an important risk factor for cardiovascular diseases]. Lijec Vjesn. 2011; 133(3-4):111-6

23. Blazek A, Rutsky J, Osei K, Maiseyeu A, Rajagopalan S. Exercise-mediated changes in high-density lipoprotein: impact on form and function. Am Heart J. 2013; 166(3):392-400.

24. Eftekhari E, Zafari A, Gholami M. Physical activity, lipid profiles and leptin. J Sport Med Phys Fitness. 2016; 56(4):465-9.

25. Cesa CC, Barbiero SM, Petkowicz RO, Martins CC, Marques RD, Andreolla $\mathrm{AA}$, et al. Effectiveness of physical exercise to reduce cardiovascular risk factors in youths: a randomized clinical trial. J Clin Med Res. 2015; 7(5):348-55.

26. Schmid H, Goelzer Neto C, Dias L, Weston A, Espíndola M, Pioner S, et al. Metabolic syndrome resolution by Roux-en-Y gastric bypass in a real world: a case control study. Rev Assoc Med Bras. 2015; 61(2):161-9.

27. Thaisetthawatkul P, Collazo-Clavell ML, Sarr MG, Norell JE, Dyck PJB. A controlled study of peripheral neuropathy after bariatric surgery. Neurology. 2004; 63(8):1462-70.
28. Scanu AM, Edelstein C. HDL: bridging past and present with a look at the future. FASEB J. 2008; 22(12):4044-54

29. Mahdy Ali K, Wonnerth A, Huber K, Wojta J. Cardiovascular disease risk reduction by raising HDL cholesterol - current therapies and future opportunities. Br J Pharmacol. 2012; 167(6):1177-94.

30. Assmann G, Gotto AM. HDL cholesterol and protective factors in atherosclerosis. Circulation. 2004; 109(1):III8-14.

31. Posse de Chaves EI, Vance DE, Campenot RB, Kiss RS, Vance JE. Uptake of lipoproteins for axonal growth of sympathetic neurons. J Biol Chem. 2000; 275(26):19883-90.

32. Rodrigues B, Santana AA, Santamarina AB, Oyama LM, Caperuto EC, de Souza CT, et al. Role of training and detraining on inflammatory and metabolic profile in infarcted rats: influences of cardiovascular autonomic nervous system. Mediators Inflamm. 2014; 2014:207131.

33. Grans CF, Feriani DJ, Abssamra MEV, Rocha LY, Carrozzi NM, Mostarda $\mathrm{C}$, et al. Resistance training after myocardial infarction in rats: Its role on cardiac and autonomic function. Arq Bras Cardiol. 2014; 103(1):60-8.

34. Smith AG, Russell J, Feldman EL, Goldstein J, Peltier A, Smith S, et al. Lifestyle intervention for pre-diabetic neuropathy. Diabetes Care. 2006; 29(6):1294-9.

35. Singleton JR, Marcus RL, Lessard MK, Jackson JE, Smith AG. Supervised exercise improves cutaneous reinnervation capacity in metabolic syndrome patients. Ann Neurol. 2015; 77(1):146-53. 